\title{
21. PRELIMINARY STUDY OF ICE-RAFTED ERRATICS AS INDICATORS OF GLACIAL ADVANCES IN THE GULF OF ALASKA
}

\author{
Roland von Huene, U. S. Geological Survey, Menlo Park, California \\ Edwin Larson, Geology Department, University of Colorado, Boulder, Colorado \\ and \\ James Crouch, U. S. Gelogical Survey, Menlo Park, California
}

\section{INTRODUCTION}

Numerous rafted pebble erratics were found in the cores recovered from the Gulf of Alaska during Leg 18 of the Deep Sea Drilling Project. The pebbles were concentrated in zones but there was little opportunity aboard ship to correlate these zones with known glacial events. This opportunity came shortly after Leg 18 ended and the North Pacific erratic abundance curve developed by Kent et al. (1971) was published. The most complete Leg 18 sequence of erratic rich zones, which occurs at Site 178, could be made to fit to their erratic abundance curve, but not uniquely. These attempts made it apparent that a more thorough analysis of Site 178 would compliment the study of Kent et al. (1971) because, in their study, the argument that all material coarser than medium sand $(>250 \mu)$ is ice rafted and not transported by currents is uncertain. An assessment of this uncertainty can be made at Site 178 by comparing the fraction between $250 \mu$ and $2 \mathrm{~mm}$ with the pebbles, since pebbles are not moved far by deep-sea currents and bioturbation. Also, many high amplitude peaks in the curves developed by Kent et al. (1971) are based on single points. This suggests that the time represented by some sampling intervals were equal to, or greater than, the duration of some periods of erratic influx. At Site 178 a sediment sequence was recovered that is about 10 times thicker than the time equivalent pelagic sequence available to Kent et al. This allows sampling across a shorter time interval and an increase of detail. Additional detail might also occur at Site 178 because it is so near the glaciers which produced icebergs in the Gulf of Alaska (Figure 1).

This study has three objectives. The first is to test the assumed ice-rafted origin for sand grains between $>250 \mu$ and $2 \mathrm{~mm}$. The second is to estimate the duration of periods of increased icebergs, and the third is to determine a detailed chronology of glacial advance and retreat that could be compared with other chronologies. As the study progressed it became apparent that the effort necessary to meet these objectives had been seriously underestimated. Therefore the results reported here are considered preliminary and more as a guide and stimulant for further work than as a final result.

\section{DESCRIPTION OF RAFTED ERRATICS}

Three groups of clasts were examined petrologically and petrographically. In the first, erratic clasts imbedded in the gray muds at Sites 178, 181, and 182 were studied to establish their provenance. Slates and graywackes make up 95 per cent of the 115 large clasts examined and the remainder are granite, granodiorite, mica shist, and metavolcanic rocks. The slates and graywackes are undoubtedly from the widespread Cretaceous and early Tertiary slate graywacke outcrops along the western and central coasts of the Gulf of Alaska. The remaining rocks are found in smaller outcrops on Kodiak Island, in Prince William Sound, and in the Chugach-St. Elias Mountains.

The clasts range in size from cobbles (three) to grains 5 $\mathrm{mm}$ across. Half of the coarser clasts are larger than $200 \mathrm{~mm}$. About 45 per cent have sharp unabraded edges on a freshly broken surface and show no recognizable faceting. Only a few of the larger clasts have glacial facets. About 50 per cent are angular with some abrasion, and of these only 15 per cent appear to have been subjected to any stream or beach environment, and less than 2 per cent are subrounded.

In the second group, material from the upper continental slope (Site 182, Core 1, core catcher) consisted of 200 small clasts including pebbles (less than $6 \mathrm{~mm}$ ), granules, and a few coarse sand grains which are mostly angular lithic fragments with freshly broken surfaces. More than 70 per cent of these fragments are slate, less than 5 per cent are plutonic or metamorphic rock fragments, and the rest are quartz grains. Faceting and chatter marks were seen on two grains.

The third group consisted of sand from the greater than $250 \mu$ split of the first 42 meters drilled at Site 178. The grains are mainly angular lithic, glass, and mineral grain fragments. As in the previous groups this material shows no signs of intergranular collision and has obviously not been in a beach or stream environment. Lithic fragments are mostly slate and graywacke with occasional pumice, dark glạss, and glass spheroids.

Undoubtedly, the angular pebbles and cobbles have been carried from the Chugach-St Elias Mountains by glaciers and then rafted in icebergs. Most of them fit the descriptions and photographs of ablation debris on the Malaspina Glacier, the largest piedmont glacier flowing into the Gulf of Alaska (Sharp, 1958). Since the coarse clasts and sand grains have the same composition and shape, they are likely to have a similar origin and history of transport.

\section{MEASUREMENTS OF ERRATIC ABUNDANCE}

The quantity of pebble erratic material was first estimated aboard the Challenger and later on shore. Shipboard counting of erratics was limited to those encountered in cutting the core. Later, pebbles were encountered during the channel sampling for sand. To increase the population, the archive core half was $\mathrm{x}$-rayed. 


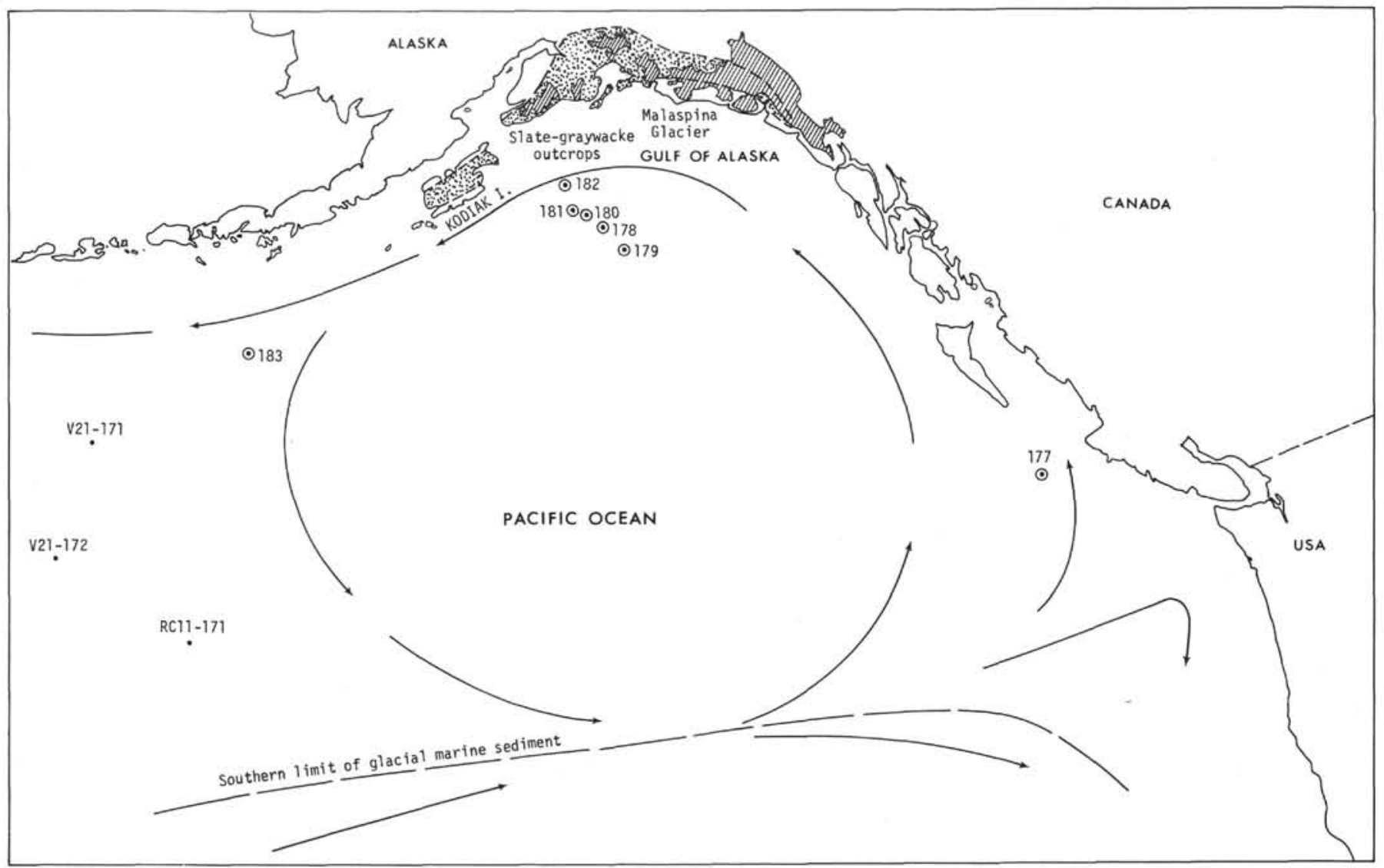

Figure 1. Gulf of Alaska with location of Lamont-Doherty Geological Observatory (•) and Deep Sea Drilling Project cores (๑), direction of currents in the Alaska current gyre, southern limit of glacial marine sediment (after Kent et al., 1971), glaciers of the Chugach-St. Elias Mountains (hatchured areas) and outcrops of the slate-graywacke belt (stippled area).

Pebbles and granules are well delineated in many $\mathrm{x}$-ray films, but in some sections the interpretation of the films was uncertain and they were verified by probing of the core. Clasts were counted on x-ray films of the archive half of the core and by inspection of the cut core in the working half.

A dry weight percentage of the fraction between $>250 \mu$ and $<2 \mathrm{~mm}$ was determined for a comparison with the pebble erratic counts. Samples were taken continuously along the center of the core but they were terminated at stratigraphic markers such as silt and ash interbeds and color changes. No samples were taken from graded silt and fine sand layers. The sampling was done by cutting a small channel whose $20 \mathrm{~cm}$ to $50 \mathrm{~cm}$ length was estimated to span no more than 3000 years. The geochronological control for Site 178 is described in the next section. Samples averaged 9 gm dry weight. In 54 duplicate samples taken to check some unusual scatter on the plots, the mean and standard deviations were 0.10 per cent and 0.13 per cent of the total sample dry weight, respectively.

\section{AGE DETERMINATIONS}

In the upper 200 meters at Site 178 , ages were determined from diatom and radiolarian biostratigraphy and from positions of remnant magnetic reversals. When combined, these methods give ages at seven points in the
Pleistocene (1.8 m.y.). A summary of the age determinations is given in Figure 2 and more complete information on the diatom and radiolarian biostratigraphy is given by Schrader and Kling (this volume).

Magnetic pole directions were determined on 28 samples and in only one sample was the field too weak to measure. All samples were demagnetized in a peak field of 50 oersteds and, since none of the pole directions were changed by this process, the remnant magnetization is probably stable.

\section{DEVELOPMENT OF ERRATIC ABUNDANCE CURVES}

When the number of pebbles per meter and the dry weight percentages of sand were graphed together as in Figure 3, the pebble curve showed some large peaks based on single samples. Within these sample sections there were often numerous granules or clusters of pebbles. Since granules can cause sudden large increases in the pebble count but comprise a relatively small volume, they were removed. Clusters of pebbles in the cores may indicate a period of abundant sea ice but they may also indicate a sudden dumping of erratics from a single berg. Icebergs often overturn as melting makes them unstable and they dump large accumulations of rock fragments exposed by ablation. The elimination of granules and some very closely clustered pebbles made the curve somewhat smoother, 


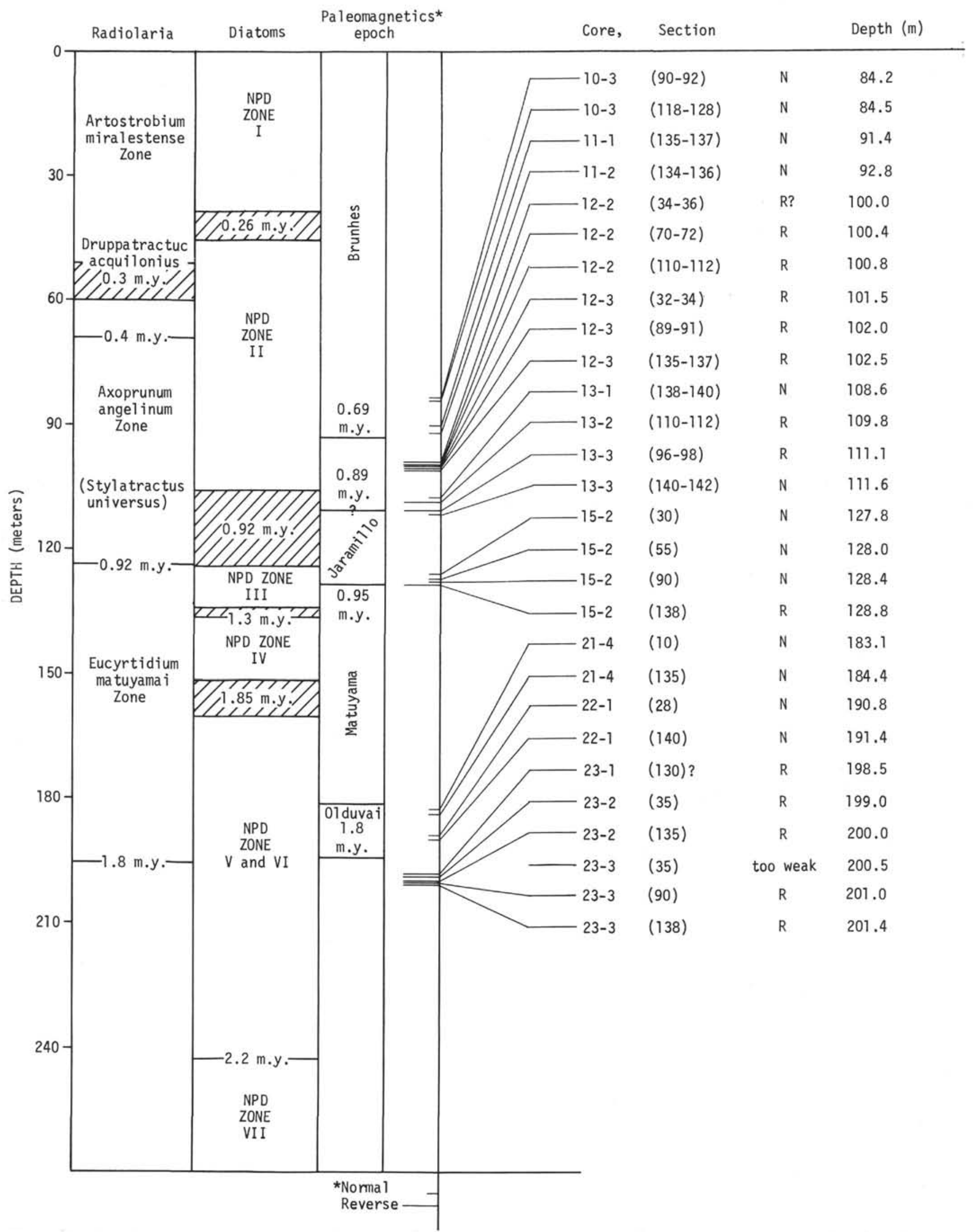

Figure 2. Age determinations on Core 178 sediment. Uncertainty in biostratigraphic boundaries shown by hatchured zones. Querried paleomagnetic polarities indicate nearly horizontal inclinations of remnant magnetism. 


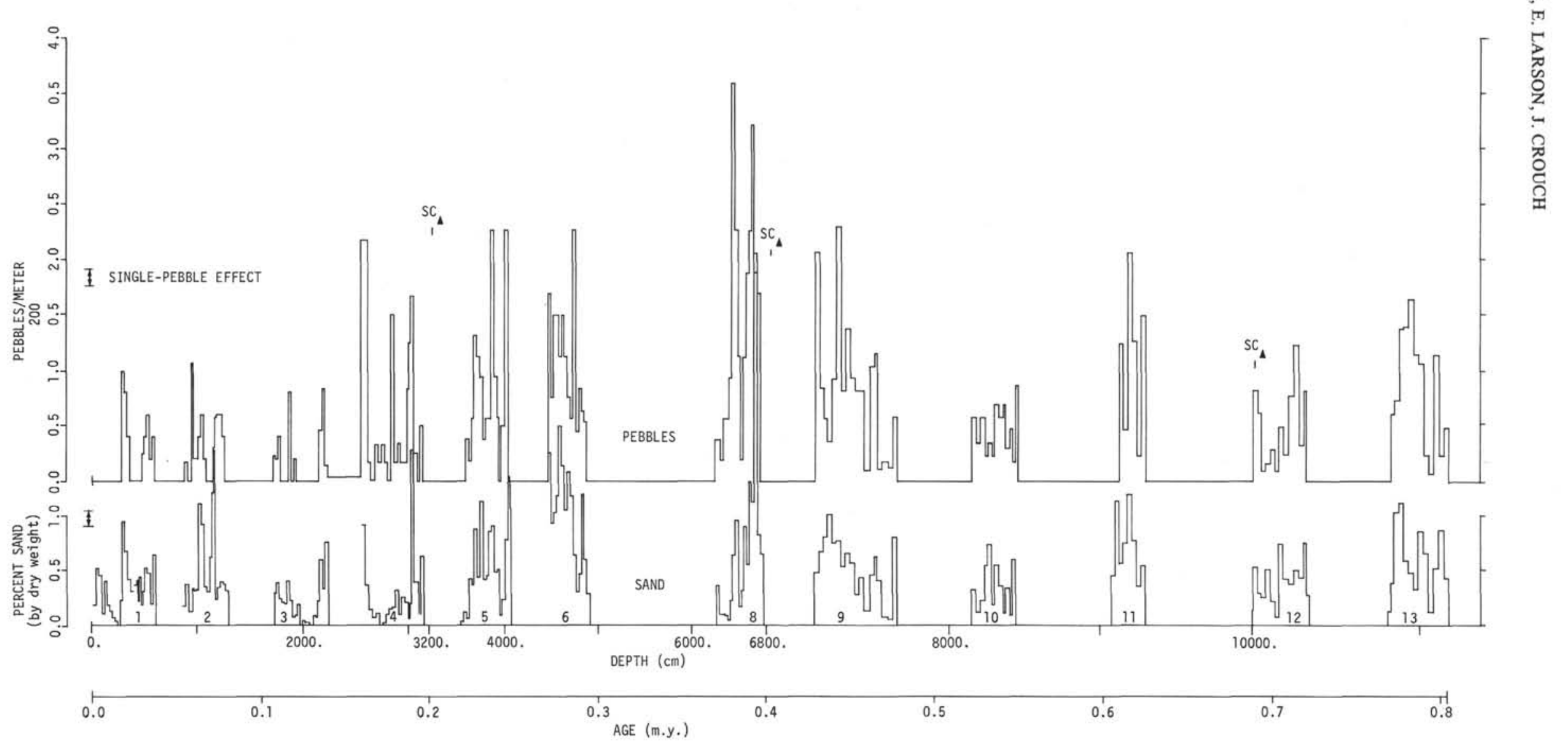

Figure 3. Graph of dry weight of sand and pebble abundance as a function of age. Each horizontal line indicates length of a channel sample from the center of Core 178. The standard deviation ( ) and general effect of a single pebble are shown at left margin SC $\Delta$ indicates point where age control is available. Age between control points is interpreted linearly. Bold numbers along sand curve are Site 178 core numbers. 
however, it still has greater variations than the sand curve as can be seen in Figure 3. Part of this variation is caused by the far greater population or number of sand grains relative to pebbles, because the number of pebbles is so small that a single pebble has a noticeable effect. The smoother configuration of the sand curve may also be influenced by the greater dispersal of sand than pebbles as a sample settles through $4 \mathrm{~km}$ of water, and possibly by limited current transport or by the effects of bioturbation. Nevertheless, more than 80 per cent of the pebble peaks and troughs in Figure 3 correspond to sand peaks and troughs. To provide a better correlation, the population of pebbles in a single sample was increased by grouping four of the sample intervals in Figure 3 as shown in Figure 4. This correlation is considered to indicate strongly the ice-rafted origin of the sand fraction.

The discontinuous curve from Site 178 was then compared to the summary curve of Kent et al. (1971) in an attempt to overcome the stringent limitations imposed by the partial core recovery from each 10 meter interval drilled. Missing sections probably span periods of numerous unrecorded fluctuations, and therefore the Site 178 data show only fragments of the record somewhere within each 10 meter segment. But the difference in character between the Site 178 curve and the summary curve of Kent et al. (1971) makes it difficult to fit one to the other. Therefore a curve specifically related to the Gulf of Alaska current gyre was constructed by combining the data developed by Kent et al. (1971) from cores RC-11-171, V-21-171, and V-21-172 (Figures 1, 3, and 5). In spite of these efforts, it is disappointingly difficult to correlate the two curves convincingly or uniquely. The curve based on the data of Kent et al. (1971) probably has broader peaks and troughs than the Site 178 curve because of its sample interval, the averaging that occurs during summation, and the greater distance of the cores used by Kent et al. (1971) from the main sources of ice (Figure 1). In RC-11-171, V-21-171, and V-21-172 the average sample intervals span 14000 , 13000 , and 8000 years respectively as compared with 1700 to 2600 year intervals at Site 178 . The distance from the source of icebergs has a filtering effect on the fluctuations of the curve. For instance, it was surprising to find an absence of pebble erratics in sediments deposited during the last 20,000 years at Site 178 even though the Malaspina Glacier shed ice into the sea during historic time (Tarr and Martin, 1914; Plafker and Miller, 1958). Filtering is shown dramatically in a comparison between eratic abundance curves for V-21-171 and V-21-172 (Kent et al. 1971). Obviously, the detail recorded in cores increases with proximity to the glacial source as does the detection of minor glacial advances.

\section{DISCUSSION}

The results of this study meet two of the three initial objectives which were to test the assumption that coarse sand is ice rafted and to estimate the duration of ice erratic influx period. The third objective, which was to establish a more detailed chronology of glacial advance and retreat, is not possible with such incomplete core recovery.

Pebble erratics have a surface character and lithology that could not have been preserved in a stream or beach environment, and therefore there is little doubt of their rafted origin. These characteristics are also seen in granules and coarse sand grains. In addition, the correlation of coarse sand with the pebble fluctuations is good, and most significant influxes of pebbles are also significant influxes of medium and coarse sand. These similarities validate the assumption that the coarse sand fraction is a reliable indicator of fluctuations in ice rafting. Site 178 is a particularly stringent test of this premise because of the presence of silt and fine sand turbidites and the close proximity of Site 178 to turbidity current channels.

The fluctuations of ice rafted material at Site 178 have a moderately strong mode at the 12,000 year and 15,000 year periods as shown in the power spectral analysis in Figure 6. This periodicity is close to the estimated duration of several glacial stades within the last major cold cycle (Mörner, 1971). The longer periodicity of the curves developed by Kent et al. (1971) may be a function of filtering caused by the much greater distance from the major area of glacial generation as well as the longer time represented by the sample interval. In fact it may not be possible to sample a core of truly pelagic origin at a close enough interval to define a 10,000 to 20,000 year periodicity, not only because of the low rates of sedimentation but also because of mixing by bioturbation.

The short periodicity and relatively large amplitude of fluctuations make it difficult to integrate the erratic abundance curve for Site 178 with the established longer period curves. It seems nearly impossible to join the Site 178 segments with sections from established curves, and the two curves are superimposed in Figure 4. What Figure 4 suggests is that a series of 15,000 year advances were superimposed on the longer major periods of ice advance indicated in lower latitudes.

A general time of intense glaciation is indicated by the increased rates of sedimentation beginning about a million years ago. If the $37 \mathrm{~m} / \mathrm{m}$.y. rate of sedimentation between 2.2 and $20 \mathrm{~m} . \mathrm{y}$. is assumed to be normal for the upper Tertiary, then at times during the last million years, rates of sedimentation were at least six times greater than normal. This corresponds well with other north Pacific observations that erratics became particularly abundant and waters became cooler about 1.0 m.y. ago (Conolly and Ewing, 1970; Kent et al., 1971). A time of most intense glaciation is suggested by increased rates of sedimentation between 0.2 and 0.4 m.y. (Figure 4).

Possibly the most significant part of this study is that it shows a potential way to determine a detailed chronology of Pleistocene glacial advances. Because of its northern latitude and the adjacent arc of glacier-covered mountains, the quantity of floating ice in the Gulf of Alaska is probably a very sensitive indicator of climatic change. The use of ice-rafted debris in studies of part climate combines the continuity of the marine record with the discrimination of alpine glaciation.

\section{ACKNOWLEDGMENTS}

We are grateful to Don Richter and George Plafker of the U. S. Geological Survey for identifying possible sources of erratic pebbles. David Hopkins stimulated this study and often discussed problems as they were encountered. 


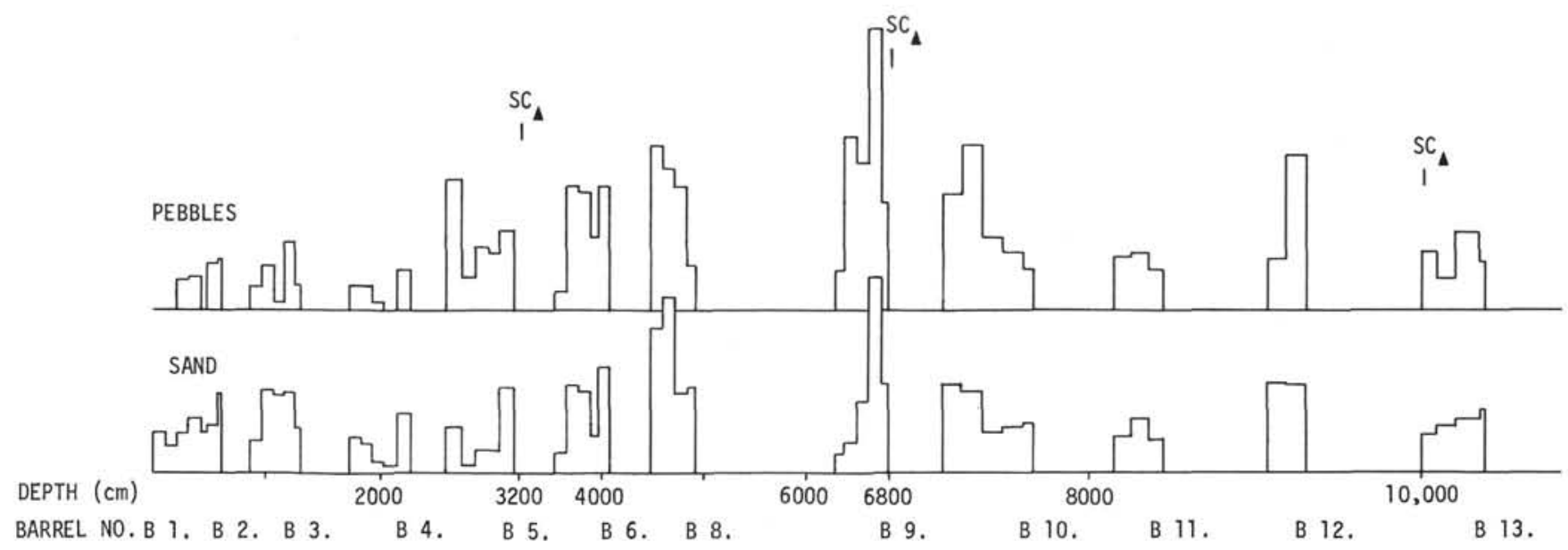

Figure 4. Graph of sand and pebble abundances shown in Figure 3 averaging successive groups of four samples to decrease the effect of a single pebble. The greater numbers of pebbles per sample and the resulting smoother pebble curve provide an easier comparison and correlation of relative sand and pebble abundances.

Reviews by David Hopkins and Richard Janda were helpful and are gratefully acknowledged.

\section{REFERENCES}

Conolly, J. R. and Ewing, M., 1970. Ice-rafted detritus in northwest Pacific deep-sea sediments. Geol. Soc. Am. Mem. 126. 219.

Kent, D., Opdyke, N. D. and Ewing, M., 1971. Climate change in the north Pacific using ice-rafted detritus as a climatic indicator. Bull. Geol. Soc. Am. 82, 2741.
Mörner, N. A., 1972. The cold/warm changes during the last ice age with special reference to the stratigraphy at Dösebacka and Ellesbo in southwest Sweden. Stockholm Contribution in Geology. 24 (4). Stockholm (Almquist and Wiksett).

Plafker, G. and Miller, D. J., 1958. Glacial features and surficial deposits of the Malaspina district, Alaska. U. S. Geol. Surv. Misc. Geol. Inv. Map I-271. Scale 1:125,000. Sharp, R. P., 1958. Malaspina Glacier, Alaska. Bull. Geol. Soc. Am. 69, 617.

Tarr, R. S. and Martin, L., 1914. Alaskan Glacier Studies. Nat. Geog. Soc. 41. 


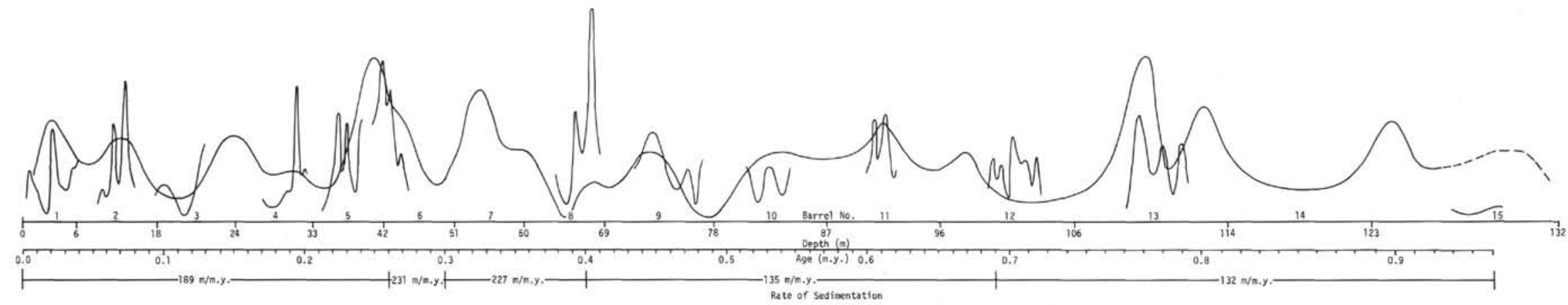

Figure 5. Summary curve of V-21-171, V-21-172, RC-11-171 (continuous line) and smoothed curve through sand data from Figure 3. Rates of sedimentation for Site 178 are given at bottom of figure. 
R. VON HUENE, E. LARSON, J. CROUCH

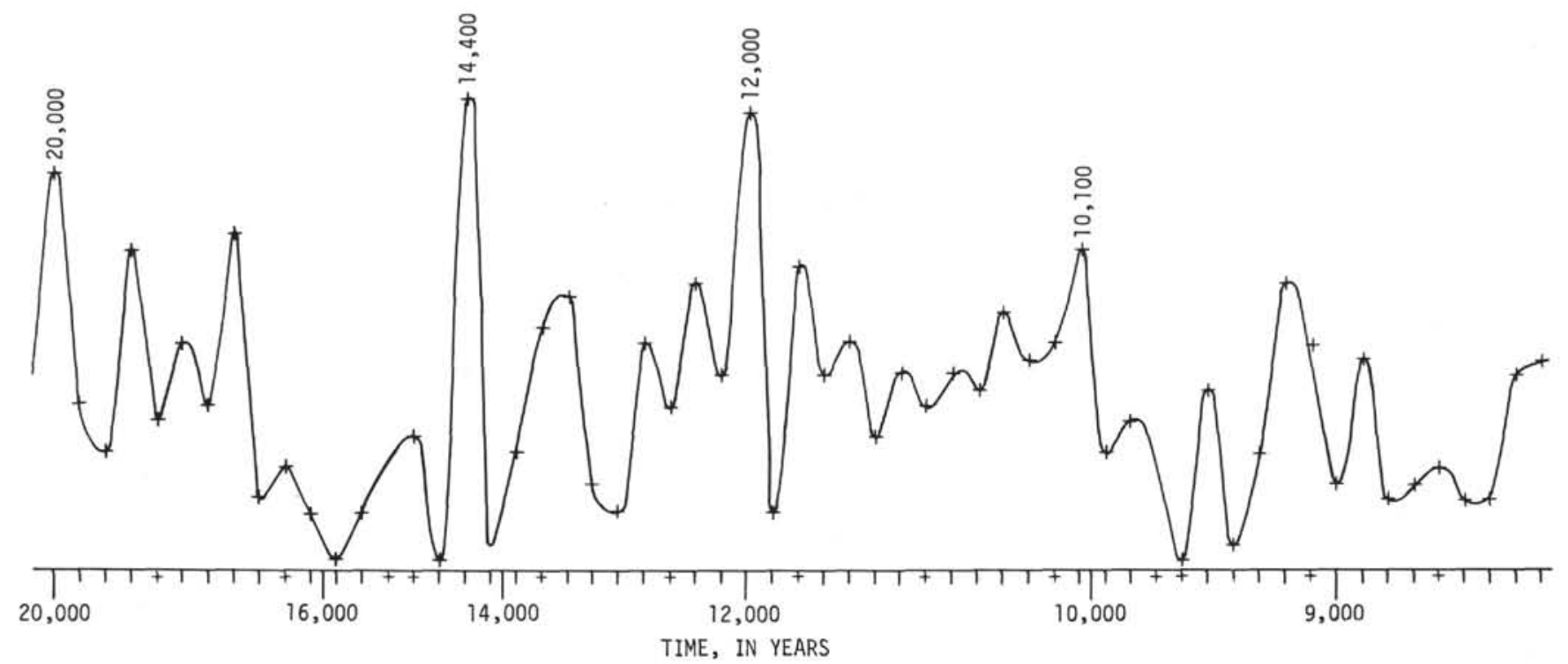

Figure 6. Power spectrum of ice-rafted sand fluctuations showing peaks at 12,000 and 14,000 year intervals. 